\title{
A Comparison of the Sexual Knowledge, Attitudes, and Behaviors of Korean College Students Studying in Korea and in the United States
}

\author{
Young-Sil Bae, Dong-Hee Kim* \\ Department Nursing, College of Nursing, Pusan National University, Yangsan, Republic of Korea \\ Email:youngsilb@hotmail.com, "dongheekim@pusan.ac.kr
}

Received 8 October 2015; accepted 27 November 2015; published 30 November 2015

Copyright () 2015 by authors and Scientific Research Publishing Inc.

This work is licensed under the Creative Commons Attribution International License (CC BY).

http://creativecommons.org/licenses/by/4.0/

(c) (i) Open Access

\begin{abstract}
The number of Korean students enrolling in universities overseas is rapidly growing. However, these populations are underrepresented in sexuality related research, despite the possibility of sexually risky behavior in overseas university students. We examined the sexual knowledge, attitudes, and behaviors of university students in Korea and studying in the United States. Data were collected-131 Korean students in Korea and in the US using a web-based self-report questionnaire system. Students in the US showed greater total sexual knowledge than students studied in Korea. There were differences in the sexual knowledge, attitude and behaviors according to general characteristics between both groups. Although students in the USA had a higher level of sexual knowledge, both students in the USA and in Korea had a low level of sexual knowledge overall.
\end{abstract}

\section{Keywords}

Culture, Sexual Knowledge, Sexual Attitude, Sexual Behavior, University Students

\section{Introduction}

There is no doubt that sexual values are influenced by disparate cultural, political, historical, and socioeconomic factors. In Western cultures, sexual behavior is often considered as a recreational activity, whereas Asian cultures view it as primarily procreative [1] [2]. Asians tend to have relatively more conservative sexual attitudes than other ethnic groups, such as Euro-Americans [3]. These culture-specific sexual values have a long history,

*Corresponding author.

How to cite this paper: Bae, Y.-S. and Kim, D.-H. (2015) A Comparison of the Sexual Knowledge, Attitudes, and Behaviors of Korean College Students Studying in Korea and in the United States. Open Journal of Nursing, 5, $1053-1062$.

http://dx.doi.org/10.4236/ojn.2015.511112 
and parents influence their children through the familial structure. Young Koreans are raised in social circumstances where sexual behavior is restricted and forbidden outside of marriage. For instance, Korean young females and males receive sexual education separately and some of schools run in the form of men's or girl' high school. Moreover, many Korean parents expect their children to dedicate themselves to study, and any association with sexual activity meets with disapproval [4]. In such environments, Korean students may suppress or inhibit their overall sexual identity, consciously or unconsciously, before attending college [5] [6].

University students belong to the late adolescence developmental stage; they are physically mature and have vigorous sexual appetite [7] [8]. Moreover, unlike high school students, university students are under less guidance from their parents so that they are able to more easily enter into relationships and associated sexual acts. Interestingly, the proportion of Korean students reporting sexual experience is rapidly growing. The sex experience of Korean university students has sharply increased from $27.6 \%$ in 2000 to $41.6 \%$ in 2010 [9]. Moreover, social interaction between Korean students increases sexual activities incrementally, as evidenced by a $58.6 \%$ rise in sexual behavior within 30 to 90 days after meeting with someone on a blind date [10] [11]. Sexual exploration brings with the possibility of negative health outcomes. Thirty-nine percent of new human immunodeficiency virus infections in 2009 occurred among adolescents and young adults aged less than 30 years old [12].

In Korea, students have a native environment that includes family, friends, peers, and media to mitigate and support their sexual development as needed. In contrast, Korean students in the US suffer anxiety and depression due to environmental changes, acculturation stress, and a liberal lifestyle that results in negative sexual attitudes and behaviors [13] [14]. For example, most international students have difficulty in seeing a doctor when they experience health problems due to language proficiency issues, the financial burden, and a lack of information or awareness regarding health services [15]. Because overseas university students remain long-term in a given place, their sexual knowledge, attitudes, and behaviors may be influenced by the domestic culture in which they are situated. Overseas university students' sexual behavior may also have an effect on domestic students' sexual health. There have been few studies on issues related to sex among overseas-born students. One previous study [16] reported that Asian-born overseas students had consistently lower levels of sexual knowledge than domestic students.

The number of Korean students enrolling in universities in the United States is rapidly growing. About twelve percent $(68,047)$ of foreign students in the US were Korean [17]. Korean students are the largest group in US international colleges and university academics [18]. However, these populations are underrepresented in sexuality related research, despite the possibility of sexually risky behavior in overseas university students. We are interested in whether Korean university students studying in the US are equipped with adequate knowledge regarding sexuality, and their sexual attitudes and behaviors are compared with those of domestic Korean students. Understanding the differences in sexual knowledge, attitudes, and behaviors between these two groups may provide insight into what preparations, including effective education, are needed for overseas university students, both domestically, and while in their international placement.

\section{Methods}

This study used a cross-sectional relational descriptive study design with a web-based self-report questionnaire.

\subsection{Participants}

Participants in this study were 131 Korean university students studying in Korea or in the USA. Sixty-four students were recruited from two universities in the USA and 67 students participated from four universities in four different cities in Korea. Inclusion criteria for the students in Korea were no experience of marriage or travel abroad for any purpose, and for students in the USA the criteria were no experience of marriage and having been studying overseas more than a year.

\subsection{Ethical Issues and Procedure}

The research protocol, including the questionnaires, was approved by the Institutional Review Board of Pusan National University (PUN IRB/2014-01-HR). A study web site was developed that allowed participants to log in, enter and save their responses, and return later to continue or complete the questionnaire. We provided a preface for the participants, which explained the purpose of the study, the rights of participants (e.g., anonymity), and clearly indicated that study participation was voluntary with participants able to withdraw at any time. 
We announced the project on the school board of each university to recruit participants from March to April, 2014. A total of 142 students in Korea or in the USA logged in the website and completed the questionnaire. However, 11 participants were excluded because they did not complete the survey. All students who completed the questionnaire were give 10-dollar gift coupon.

\subsection{Measures}

We used a web-based self-report instrument measuring sexual knowledge, sexual attitudes, and sexual behaviors, and also collected socio-demographic information such as age, gender, grade, living arrangements, and economic status.

\subsubsection{Sexual Knowledge}

For sexual knowledge assessment, we used a sexual knowledge scale developed by Woo [19]. This scale consists of 39 items pertaining four domains: eight items pertaining to sexual organs, nine items for pregnancy and delivery, 15 items for sexual health issues, and seven items for sexual acts. Each question was evaluated as true or false, and scores were created by adding the number of correct answers. The total number of correct answers to these 39 sexual knowledge questions reflected the degree of knowledge, with higher scores indicating greater knowledge. The internal consistency reliability for this scale was 0.87 (Cronbach's alpha).

\subsubsection{Sexual Attitudes}

A modified version of the sexual attitudes scale developed by Woo [19] was used for sexual attitude measurement. After deletion of items pertaining to prostitution, the following 51 items, in six domains were included in the study: 13 items regarding awareness of marriage and sex, nine items for abortion, nine items for marriage and delivery, nine items for virginal purity, and 11 items for contraception. Each item was rated on a 5-point Likert scale with labels at each scale point (from $1=$ strongly disagree to $5=$ strongly agree). Higher scores indicated less conservative sexual attitudes. The internal consistency reliability for this scale was 0.72 (Cronbach's alpha).

\subsubsection{Sexual Behaviors}

To measure sexual behaviors, the students were asked about their experience of sexual acts, including friendship, kissing/embracing, petting, sexual relationships, pregnancy, abortion, childbirth, sexually transmitted disease, sexual violence, shameful sexual acts during childhood, sexual acts caused by alcohol, sexual acts occurring through ignorance, pornographic magazine/video contact, and phone sex. We used the sexual behavior and impulse scales developed by Woo [19]. The sexual behavior scales consisted of 14 items, with each item rated on a five-point scale, labeled at each scale point (from 1 = never to 5 = always). Higher scores reflected a tendency toward more unrestricted and less conservative sexual behavior. The internal consistency reliability for this scale was 0.82 (Cronbach’s alpha).

\subsection{Statistical Analysis}

Data were analyzed using SPSS version 21.0 (IBM SPSS Inc., Chicago, IL). To examine the differences between group variables, t-tests, ANOVAs, and Scheffé tests were performed. The Pearson correlation coefficient was used to analyze the relationships among sexual knowledge, attitudes, and behaviors. A p value of $<0.05$ was considered significant.

\section{Results}

The participants were 131 Korean students including 64 students studying in the U.S. and 67 students studying in Korea. For students in the US 59.4\% were over 21 years old, 51.6\% were female, $48.4 \%$ were freshmen, and $56.3 \%$ were cohabiting. Additionally, 68.7\% reported a "medium" economic status. For the students in Korea, 43.3\% were 19 years old, $56.7 \%$ were male, $52.2 \%$ were freshmen, and $67.2 \%$ were cohabiting. Additionally, $59.7 \%$ of this group reported a "medium" economic status.

There were no statistically significant differences between students in the Korea and in the U.S. in gender $(\mathrm{t}=$ $-0.94, p=0.347)$, grade $\left(\chi^{2}=3.88, p=0.274\right)$, living arrangements $(t=1.65, p=0.199)$, and economic status ( $t$ 
$=1.16, \mathrm{p}=0.362)$, but there was in age $\left(\chi^{2}=18.78, \mathrm{p}<0.001\right)$. To adjust for age we used analysis of covariance to determine whether there were any differences in the scores of sexual knowledge, attitudes, and behaviors between students in the U.S.A. and in Korea.

\subsection{Sexual Knowledge}

Differences in sexual knowledge between students in the U.S.A. and in Korea are shown in Table 1. The total score of sexual knowledge for students in the U.S.A. was significantly higher than for those in Korea $(\mathrm{F}=4.16$, $\mathrm{p}=0.044$ ). Among the subcategories, students in the U.S.A. scored significantly higher in the category of knowledge about sexual acts than those in Korea $(\mathrm{F}=4.16, \mathrm{p}=0.044)$.

\subsection{Sexual Attitudes}

Differences in sexual attitudes between students in the USA and in Korea are shown in Table 2. Although students in the USA had a lower total sexual attitude score than students in Korea, the difference was not significant $(\mathrm{F}=1.86, \mathrm{p}=0.175)$.

\subsection{Sexual Behaviors}

Differences in sexual behaviors between students in the USA and in Korea are shown in Table 3. There was no significant difference in the total sexual behavior score $(F=0.03, p=0.868)$. However, for the subcategories, students in the USA scored significantly lower than those in Korea for the items related to sexually transmitted disease $(F=7.12, p=0.009)$, sexual violence $(F=6.03, p=0.015)$, and sexual acts caused through ignorance ( $\mathrm{F}$ $=6.25, \mathrm{p}=0.014)$. Shameful sexual acts scored higher for students in the USA versus those in Korea $(\mathrm{F}=5.93$, $\mathrm{p}=0.016)$.

Table 1. Sexual knowledge of Korean university students in the US and Korea $(\mathrm{N}=131)$.

\begin{tabular}{cccc}
\hline & Students in U.S. & Students in Korea & \multirow{2}{*}{ Variables $(p)^{*}$} \\
\cline { 2 - 3 } & $\mathrm{M} \pm \mathrm{SD}$ & $\mathrm{M} \pm \mathrm{SD}$ & \\
\hline Sexual knowledge & $22.09 \pm 6.76$ & $18.32 \pm 8.12$ & $4.16(0.044)$ \\
Sexual organ & $4.89 \pm 1.11$ & $4.49 \pm 1.87$ & $2.90(0.091)$ \\
Pregnancy and delivery & $4.92 \pm 1.81$ & $4.56 \pm 2.33$ & $0.61(0.436)$ \\
Health on sex & $8.79 \pm 4.49$ & $6.52 \pm 4.25$ & $2.98(0.087)$ \\
Sexual act & $3.48 \pm 1.68$ & $2.74 \pm 1.82$ & $4.21(0.042)$ \\
\hline
\end{tabular}

*covariance: age.

Table 2. Sexual attitudesof Korean university students in the US and Korea ( $N=131)$.

\begin{tabular}{cccc} 
Variables & Students in US & Students in Korea & F $(p)^{*}$ \\
\cline { 2 - 3 } Sexual attitude & $\mathrm{M} \pm \mathrm{SD}$ & $\mathrm{M} \pm \mathrm{SD}$ & \\
\hline Awareness of marriage and sex & $2.82 \pm 0.25$ & $2.87 \pm 0.34$ & $1.86(0.175)$ \\
Abortion & $2.59 \pm 0.34$ & $2.92 \pm 0.39$ & $1.72(0.193)$ \\
Marriage and delivery & $2.55 \pm 0.38$ & $2.68 \pm 0.65$ & $0.56(0.457)$ \\
Virginal purity & $2.51 \pm 0.93$ & $2.63 \pm 0.55$ & $1.41(0.237)$ \\
Contraception & $2.98 \pm 0.48$ & $2.54 \pm 0.69$ & $0.26(0.608)$ \\
\end{tabular}

*covariance: age. 
Table 3. Sexual behaviorsof Korean university students in the US and Korea ( $N=131)$.

\begin{tabular}{cccc}
\hline Variables & Students in US & Students in Korea & \multirow{2}{*}{ F (p)* } \\
\cline { 2 - 3 } & M \pm SD & M \pm SD & \\
Sexual behaviors & $2.09 \pm 0.57$ & $2.10 \pm 0.55$ & $0.03(0.868)$ \\
Friendship with opposite sex & $4.19 \pm 1.00$ & $4.22 \pm 0.93$ & $0.26(0.613)$ \\
Kiss/embracing & $3.83 \pm 1.52$ & $4.06 \pm 1.02$ & $1.92(0.168)$ \\
Petting & $3.05 \pm 1.70$ & $2.75 \pm 1.51$ & $0.80(0.374)$ \\
Sexual relationships & $2.80 \pm 1.78$ & $2.45 \pm 1.59$ & $1.14(0.287)$ \\
Pregnant & $1.30 \pm 1.00$ & $1.24 \pm 0.65$ & $0.02(0.886)$ \\
Abortion & $1.25 \pm 0.97$ & $1.34 \pm 0.89$ & $1.23(0.269)$ \\
Delivery & $1.19 \pm 0.85$ & $1.22 \pm 0.57$ & $0.35(0.553)$ \\
Sex violence & $1.00 \pm 0.00$ & $1.19 \pm 0.55$ & $7.12(0.009)$ \\
Sexual transmitted disease & $1.00 \pm 0.00$ & $1.33 \pm 0.91$ & $6.03(0.015)$ \\
Shameful sexual acts during childhood & $1.66 \pm 1.32$ & $1.21 \pm 0.64$ & $5.93(0.016)$ \\
Sexual acts caused by alcohol & $1.55 \pm 1.15$ & $1.73 \pm 1.18$ & $0.93(0.336)$ \\
Sexual acts against ignorance & $1.06 \pm 0.24$ & $1.34 \pm 0.68$ & $6.25(0.014)$ \\
Porno magazine/porno video contact & $3.05 \pm 1.40$ & $3.07 \pm 1.43$ & $0.57(0.453)$ \\
Phone sex & $2.35 \pm 1.49$ & $2.25 \pm 1.29$ & $0.17(0.678)$ \\
\hline
\end{tabular}

*covariance: age.

\subsection{Differences in Sexual Knowledge, Attitudes, and Behaviors According to General Characteristics of Students in Korea}

Scores of sexual knowledge, attitudes, and behaviors according to general characteristics, including correlations among sexual knowledge, attitudes, and behaviors for students in Korea are shown in Table 4. Sexual knowledge was significantly different according to school grade. The scores of seniors were highest of all $(\mathrm{F}=3.21, \mathrm{p}$ $=0.029)$, while there were no significant differences according to the Scheffé test $(p>0.05)$. There were no correlations among sexual attitudes according to general characteristics. Sexual behavior differed according to economic status $(\mathrm{F}=2.69, \mathrm{p}=0.009)$. There were no correlations among sexual knowledge, attitudes, and behaviors in Korea.

\subsection{Differences in Sexual Knowledge, Attitudes, and Behaviors According to General Characteristics of Students in the USA}

Scores of sexual knowledge, attitudes, and behaviors according to general characteristics, including correlations among sexual knowledge, attitudes, and behaviors in the USA are shown in Table 5 . There were no correlations among sexual knowledge according to general characteristics. Sexual attitude differed significantly according to school grade $(F=3.87, p=0.013)$. Based on a Scheffé test, the scores of seniors were significantly higher than those of freshmen $(\mathrm{p}<0.05)$. There was a significant difference in sexual behavior according to school grade ( $\mathrm{F}$ $=6.57, \mathrm{p}=0.001$ ). Based on a Scheffé test, the scores of senior were significantly higher than those of freshmen and sophomores $(\mathrm{p}<0.05)$. A significant positive correlation was shown between sexual knowledge and behavior $(\mathrm{r}=0.39, \mathrm{p}=0.002)$.

\section{Discussion}

In spite of a high level of depression, anxiety, and stress related to acculturation or general life events, many international students do not use the available health services in their university or in the community [15]. Based on the conservative attitudes toward sexuality in Asia, one would expect university students to be more hesitant 
Table 4. Differences in sexual knowledge, sexual attitudes and sexual behaviors according to general characteristics of the Korean university students in Korea $(\mathrm{N}=67)$.

\begin{tabular}{|c|c|c|c|c|c|c|}
\hline \multirow{2}{*}{ Variables } & \multicolumn{2}{|c|}{ Sexual Knowledge } & \multicolumn{2}{|c|}{ Sexual Attitude } & \multicolumn{2}{|c|}{ Sexual Behavior } \\
\hline & $\mathrm{M} \pm \mathrm{SD}$ & $F / t(p)$ & $\mathrm{M} \pm \mathrm{SD}$ & $\mathrm{F} / \mathrm{t}(p)$ & $\mathrm{M} \pm \mathrm{SD}$ & $\mathrm{F} / \mathrm{t}(p)$ \\
\hline \multicolumn{7}{|l|}{ Age } \\
\hline 18 & $17.25 \pm 10.03$ & 0.29 & $2.68 \pm 0.42$ & 0.92 & $2.30 \pm 0.63$ & 1.55 \\
\hline 19 & $17.79 \pm 8.15$ & $(0.832)$ & $2.90 \pm 0.18$ & $(0.436)$ & $2.12 \pm 0.54$ & $(0.210)$ \\
\hline 20 & $18.26 \pm 7.35$ & & $2.89 \pm 0.48$ & & $1.86 \pm 0.54$ & \\
\hline$\geq 21$ & $20.00 \pm 8.34$ & & $2.91 \pm 0.38$ & & $2.20 \pm 0.51$ & \\
\hline \multicolumn{7}{|l|}{ Gender } \\
\hline Male & $19.02 \pm 7.54$ & 0.80 & $2.89 \pm 0.39$ & 0.53 & $2.19 \pm 0.58$ & 1.46 \\
\hline Female & $17.41 \pm 8.87$ & $(0.425)$ & $2.85 \pm 0.28$ & $(0.617)$ & $1.99 \pm 0.50$ & $(0.149)$ \\
\hline \multicolumn{7}{|l|}{ Grade level } \\
\hline Freshman & $16.20 \pm 7.62$ & 3.21 & $2.82 \pm 0.35$ & 2.60 & $2.04 \pm 0.59$ & 1.64 \\
\hline Sophomore & $18.42 \pm 9.00$ & $(0.029)$ & $2.91 \pm 0.27$ & $(0.060)$ & $2.11 \pm 0.50$ & $(0.190)$ \\
\hline Junior & $23.12 \pm 6.70$ & & $2.77 \pm 0.17$ & & $2.47 \pm 0.47$ & \\
\hline Senior & $25.20 \pm 2.77$ & & $3.23 \pm 0.56$ & & $1.90 \pm 0.40$ & \\
\hline \multicolumn{7}{|l|}{ Living arrangement } \\
\hline With someone & $18.15 \pm 7.95$ & -0.24 & $2.90 \pm 0.37$ & 1.05 & $2.02 \pm 0.50$ & -1.78 \\
\hline Alone & $18.68 \pm 8.64$ & $(0.806)$ & $2.81 \pm 0.27$ & $(0.297)$ & $2.27 \pm 0.61$ & $(0.079)$ \\
\hline \multicolumn{7}{|l|}{ Economic status } \\
\hline High & $19.81 \pm 7.76$ & 1.23 & $2.95 \pm 0.42$ & 1.57 & $2.31 \pm 0.58$ & 2.74 \\
\hline Medium & $17.32 \pm 8.30$ & $(0.221)$ & $2.82 \pm 0.27$ & $(0.121)$ & $1.95 \pm 0.48$ & $(0.008)$ \\
\hline \multicolumn{7}{|l|}{ Correlation r $(p)$} \\
\hline Sexual Attitude & & $0.54(0.665)$ & & & & \\
\hline Sexual Behavior & & $0.07(0.586)$ & & & $0.08(0.529)$ & \\
\hline
\end{tabular}

before using health services for sex-related health problems. This could be a simple health problem for the international student him/herself but could result in a serious domestic health issue by, for example, spreading sexually transmitted disease. Thus, we compared the sexual knowledge, attitudes, and behaviors of Korean university students attending college in the USA with those doing so in Korea.

We expected students in the USA would have a higher level of sexual knowledge, and less conservative sexual attitudes and behaviors than those in Korea because sexuality was more pervasive in US society than in Korea. Scores of total sexual knowledge for students in the USA were significantly higher than those in Korea, but there were no significant differences between students in the US and Korea in total scores for sexual attitudes and behaviors. Because of the lack of previous studies that have compared those sexual concepts among the same ethic population, living in different nations, we are limited in the comparisons we can make. One possible interpretation is related to the purpose of studying in the USA. In this study, we included Koreans who had student visa. We assumed that many of the students studying in the US would be the most able students, having strong academic motivations. To study in the US, they would have spent considerable effort, including learning English, as well as investing time in obtaining financial support. Therefore, students in the U.A would be expected to control their sexual impulses.

One interesting fact is that previous studies [20] [21] have reported that greater sexual knowledge leads to more frequent sexual intercourse, use of pornography, and nontraditional behavior, including drug usage, binge drinking, and failing to use birth control. Otherwise, Kim et al. [22] reported no correlation between sexual 
Table 5. Differences in sexual knowledge, sexual attitudes and sexual behaviors according to general characteristics of the Korean university students in the US ( $\mathrm{N}=64)$.

\begin{tabular}{|c|c|c|c|c|c|c|}
\hline \multirow{2}{*}{ Variables } & \multicolumn{2}{|c|}{ Sexual Knowledge } & \multicolumn{2}{|c|}{ Sexual Attitude } & \multicolumn{2}{|c|}{ Sexual Behavior } \\
\hline & $\mathrm{M} \pm \mathrm{SD}$ & $F / t(p)$ & $\mathrm{M} \pm \mathrm{SD}$ & $\mathrm{F} / \mathrm{t}(p)$ & $\mathrm{M} \pm \mathrm{SD}$ & $\mathrm{F} / \mathrm{t}(p)$ \\
\hline \multicolumn{7}{|l|}{ Age } \\
\hline 18 & $21.33 \pm 5.77$ & 1.75 & $2.54 \pm 0.32$ & 1.58 & $2.40 \pm 0.04$ & 1.72 \\
\hline 19 & $19.06 \pm 7.68$ & $(0.166)$ & $2.83 \pm 0.24$ & $(0.204)$ & $1.83 \pm 0.42$ & $(0.173)$ \\
\hline 20 & $21.00 \pm 5.45$ & & $2.89 \pm 0.17$ & & $2.27 \pm 0.75$ & \\
\hline$\geq 21$ & $23.57 \pm 6.47$ & & $2.83 \pm 0.26$ & & $2.13 \pm 0.58$ & \\
\hline \multicolumn{7}{|l|}{ Gender } \\
\hline Male & $21.67 \pm 6.59$ & 0.47 & $2.81 \pm 0.28$ & -0.49 & $2.13 \pm 0.59$ & 0.52 \\
\hline Female & $22.48 \pm 7.00$ & $(0.637)$ & $2.83 \pm 0.22$ & $(0.627)$ & $2.05 \pm 0.56$ & $(0.606)$ \\
\hline \multicolumn{7}{|l|}{ Grade level } \\
\hline Freshman $^{\mathrm{a}}$ & $21.03 \pm 7.50$ & 2.66 & $2.72 \pm 0.25$ & 3.84 & $2.00 \pm 0.40$ & 5.70 \\
\hline Sophomore ${ }^{b}$ & $21.21 \pm 5.43$ & $(0.056)$ & $2.92 \pm 0.17$ & $(0.014)$ & $1.82 \pm 0.51$ & $(0.002)$ \\
\hline Junior $^{\mathrm{c}}$ & $28.57 \pm 4.27$ & & $2.84 \pm 0.36$ & $\mathrm{a}<\mathrm{d} \dagger$ & $2.15 \pm 0.51$ & $\mathrm{a}<\mathrm{d}$ \\
\hline Senior $^{d}$ & $22.08 \pm 5.74$ & & $2.95 \pm 0.16$ & & $2.61 \pm 0.76$ & $\mathrm{~b}<\mathrm{d} \dagger$ \\
\hline \multicolumn{7}{|l|}{ Living arrangement } \\
\hline With someone & $21.61 \pm 7.03$ & -0.64 & $2.80 \pm 0.26$ & -0.95 & $2.14 \pm 0.62$ & 0.76 \\
\hline Alone & $22.71 \pm 6.47$ & $(0.522)$ & $2.86 \pm 0.23$ & $(0.348)$ & $2.03 \pm 0.51$ & $(0.448)$ \\
\hline \multicolumn{7}{|l|}{ Economic status } \\
\hline High & $22.50 \pm 6.33$ & 0.32 & $2.78 \pm 0.28$ & -0.85 & $2.17 \pm 0.61$ & 0.73 \\
\hline Medium & $21.90 \pm 7.01$ & $(0.749)$ & $2.84 \pm 0.24$ & $(0.397)$ & $2.06 \pm 0.56$ & $(0.471)$ \\
\hline \multicolumn{7}{|l|}{ Correlation r(p) } \\
\hline Sexual Attitude & & $0.20(0.116)$ & & & & \\
\hline Sexual Behavior & & $0.39(0.002)$ & & & $0.23(0.071)$ & \\
\hline
\end{tabular}

†Scheffe test.

knowledge and behavior. In contrast, Woo et al. [23] showed a positive correlation between sexual knowledge and sexual behavior in American university students, but no correlation in Korean students. The results from the present study showed greater sexual knowledge was correlated with a higher level of sexual behavior among students in the U.S., but not in Korea. There is a need for further study to identify whether this is an influence of culture or ethnic characteristics.

Although the sexual knowledge scores of students in the USA were significantly higher than those in Korea, the scores showed but a moderate level of knowledge, with a mean of $46.2 \%$ - $56.4 \%$ correct answers. Compared with a previous study [23] using the same knowledge scale as the present study, the level of sexual knowledge of students in this study was similar. In Korea, there are regulations regarding sexual education in high school. Fifteen class hours per year has been obligatory. However, routine sexual education is unlikely to reflect the specific educational needs of learners [24] [25]. Because a low level of sexual health knowledge is related to the incidence of unexpected pregnancy or HIV/STI transmission [16] [26], health care providers and schoolteachers must strive to provide young adults with sufficient accurate knowledge of sexuality. This is not a domestic issue. Departments responsible for international students should also heed this point and improve sexual knowledge by the provision of suitable programs. Such programs should be on the basis of not only international students' own culture, but also specific national characteristics, such as common sexually transmitted diseases, 
homosexual culture, and so on.

In this study, Korean college students in the US demonstrated more conservative attitudes and behaviors than domestic students studying in Korea. What factors could influence such conservative sexual attitudes and behaviors? First, the elementary and middle school years are when students begin to establish a sexual identity and develop their primary and secondary sexual characteristics [27] [28]. During high school and college, individuals continue to define and build their sexual profile from social interactions, family background, moral values, educational standards, and cultural settings. In effect, both student groups' sexual attitudes and behaviors could be hampered by conservative sociocultural influences, as they transit scholastically [29]. This result is consistent with previous studies [23] [30] that compared North American to Asian university students; Asians possess lower sexual knowledge, and more conservative attitudes and behaviors than other student groups.

Further studies might highlight the lack of, and need for, sex education as Korean students enroll in college. Students' attitudes and behaviors related to promiscuity, dating, intercourse, and pregnancy could be skewed toward risky or unsafe actions because of their conservative sexual values. Further, adolescents born overseas, and living in the US six years or less, face increased peer pressures toward harmful, abnormal, or even violent sexual behavior [27] [31]. Furthermore, these studies point out that students born overseas face a raised level of risky sexual behaviors, such as unprotected intercourse, preteen sex, anal sex, multiple or high-risk sex partners, sexually transmitted diseases, and sex for drugs or money.

According to previous studies [22] [32], economic status and social grade are significant in the development of a student's sexual identity. Their findings have revealed that students demonstrate improved overall sexual awareness if subject to financial and family stability. In addition, Franklin and Dotge [33] supported this point with a comparison of sexual environmental changes between Korean college freshman and upperclassmen. Consistent with our findings, upperclassmen have improved sexual knowledge, attitudes, and behavior. This is because senior graduates have had more time to establish and broaden their sexuality versus incoming students, through acculturation, social network orientation, and individualism or collectivism.

Our study has several limitations. First, the findings cannot be generalized to the whole population, despite our attempts to recruit Korean students through six different universities located in diverse cities in Korea and in the U.S. Second, we did not assess the motivation or purpose for studying overseas, that is, whether studying overseas was the student's own choice or whether he or she followed someone else's decision. This motivation could influence sexual behaviors even if the overseas students were exposed to attractive sexual-cultural environments. Future studies would benefit from diversity in the population investigated. Corresponding studies would be needed for Korean adolescents or younger adults studying in the USA, Europe, or other countries in Asia, to offer a more global perspective on sexual knowledge, attitudes, and behaviors. The role of additional factors should also be considered, including the motivation for studying overseas and social factors like the support and influence of domestic friends.

Although Korean university students in the US had greater sexual knowledge than those studying in Korea, there were no significant differences in total scores assessing sexual attitudes and behaviors between the two groups in the present study. Additional studies would be needed to consider other factors and cultural enculturation. Furthermore, because both students in the USA and in Korea demonstrated a low level of sexual knowledge, enhanced sexual health strategies should be formulated for Korea, and overseas where international students study.

\section{References}

[1] Ho, C.C., Singam, P., Hong, G.E. and Zainuddin, Z.M. (2011) Male Sexual Dysfunction in Asia. Asian Journal of Andrology, 13, 537-542. http://dx.doi.org/10.1038/aja.2010.135

[2] Kalra, G., Tandon, A. and Rao, S. (2014) Sexual Disorders in Asians: A Review. Asian Journal of Psychiatry, 7, 8082. http://dx.doi.org/10.1016/j.ajp.2013.11.010

[3] Meston, C.M., Trapnell, P.D. and Gorzalka, B.B. (1998) Ethnic, Gender, and Length of Residency Influences on Sexual Knowledge and Attitudes. Journal of Sex Research, 35, 176-188. http://dx.doi.org/10.1080/00224499809551931

[4] Youn, G. (2001) Perceptions of Peer Sexual Activities in Korean Adolescents. Journal of Sex Research, 38, 352-360. http://dx.doi.org/10.1080/00224490109552106

[5] Choi, J.H., Kim, K.E. and Shin, M.A. (2010) Contraceptive Knowledge, Contraceptive Attitude, and Contraceptive Use among College Students: Function of Gender, Age, and Residence. Korean Association of Human Ecology, 19, 
511-522. http://dx.doi.org/10.5934/KJHE.2010.19.3.511

[6] Sohn, A.R. and Cheon, S.S. (2005) Comparing Sexual Attitude, Sexual Initiation and Sexual Behavior by Gender in Korean College Students. Health and Social Science, 18, 73-100.

[7] Erikson, E. (1968) Identity: Youth and crisis. Norton, New York.

[8] Tasker, F. and McCann, D. (1999) Affirming Patterns of Adolescent Sexual Identity: The Challenge. Journal of Family Therapy, 21, 30-54. http://dx.doi.org/10.1111/1467-6427.00102

[9] Kim, E.M., Yoo, S.J. and Song, M.R. (2013) Correlation between History of Exposure to Obscene-Material, Sexual Attitudes and Intercourse Experience among University Students. Journal of Korean Academy of Fundamentals of Nursing, 20, 18-26. http://dx.doi.org/10.7739/jkafn.2013.20.1.18

[10] Choi, M.J. and Kong, M.H. (2007) The Development of Sex Education Program for Improving Sexual Subjectivity of Adolescents: Focused on Girls’ High School Students. Journal of Women's Studies, 18, 129-185.

[11] Ko, Y.S. (2001) A Study on Male and Female University Students' Sexual Attitude and Sexual Behavior. PhD Dissertation, Ewha Womans University, Seoul.

[12] Prejean, J., Song, R., Hernandez, A., Ziebell, R., Green, T., Walker, F., et al. (2011) Estimated HIV Incidence in the United States, 2006-2009. PLoS ONE, 6, e17502. http://dx.doi.org/10.1371/journal.pone.0017502

[13] Byno, L.H., Mullis, R.L. and Mullis, A.K. (2009) Sexual Behavior, Sexual Knowledge and Sexual Attitudes of Emerging Adult Women: Implications for Working with Families. Journal of Family Social Work, 12, 309-322. http://dx.doi.org/10.1080/10522150903030162

[14] Noland, R.M., Bass, M.A., Keathley, R.S. and Miller, R. (2009) Is a Little Knowledge a Good Thing? College Students Gain Knowledge, but Knowledge Increase Does Not Equal Attitude Change Regarding Same Sex Sexual Orientation and Gender Reassignment Surgery in Sexuality Courses. American Journal of Sexuality Education, 4, 139-157. http://dx.doi.org/10.1080/15546120903001399

[15] Jin, X.L., Kim, J.S. and Kim, D.H. (2011) A Comparison of Health-Promoting Behavior of Han-Chinese to Korean Chinese University Student in Korea. Journal of Korean Society of School Health, 24, 89-98.

[16] Song, A., Richters, J., Crawford, J. and Kippax, S. (2005) HIV and Sexual Health Knowledge and Sexual Experience among Australian-Born and Overseas-Born Students in Sydney. Journal of Adolescent Health, 37, 243.e9-243.e14. http://dx.doi.org/10.1016/j.jadohealth.2004.08.032

[17] Institute of International Education (2013/2014) Special Reports: Community College Data Resource. http://www.iie.org/Research-and-Publications/Open-Doors/Data/Community-College-Data-Resource/International-Stu dents/International-Students-Top-Places-Origin-2013-14

[18] Park, S.B., Cho, K.J. and Lee, M.H. (2007) Sexual Attitude and Sexual Behavior of the Chinese Korean University Students. Journal of East-West Nursing Research, 13, 57-65.

[19] Woo, N.S. and Ga, Y.H. (2005) A Study on of the Sexual Knowledge, Sexual Attitudes and Sexual Behavior in Korean and American College Students. Korean Journal of Woman Psychology, 10, 113-133.

[20] Brandhorst, S.R., Ferguson, B., Sebby, R.A. and Weeks, R. (2012) The Influence of Peer Sexual Activity upon College Students' Sexual Behavior. North American Journal of Psychology, 14, 111-122.

[21] Jeong, G.S., Lee, H.Y. and Rhee, S.J. (2004) Sexual Knowledge, Attitudes and Behaviors of College Students and Effects of Sexual Education on Sexual Knowledge and Attitude. Journal of Korean Society Health Education and Promotion, 21, 45-68.

[22] Kim, J.H. and Kim, K.S. (2008) The Effects of College Students' Sexual Knowledge and Sexual Attitudes on Their Sexual Behavior. Korean Journal of Family Welfare, 13, 123-138.

[23] Woo, J.S., Brotto, L.A. and Gorzalka, B.B. (2012) The Relationship between Sex Guilt and Sexual Desire in a Community Sample of Chinese and Euro-Canadian Women. Journal of Sex Research, 49, 290-298.

[24] Lee, H.J. (2013) Analysis on the Perception and the Demand of School Sex-Education of Elementary, Middle and High School Students. Journal of Educational Research, 11, 239-268.

[25] Lee, I.S., Jeon, M.Y., Kim, Y.H. and Jung, M.S. (2000) Knowledge in Sex and Needs of Sex Education among Community College Students. Journal of Korea Community Health Nursing Academic Society, 14, 382-395.

[26] Wang, R.H., Wang, H.H. and Hsu, M.T. (2003) Factors Associated with Adolescent Pregnancy: A Sample of Taiwanese Female Adolescents. Public Health Nursing, 20, 33-41. http://dx.doi.org/10.1046/j.1525-1446.2003.20105.x

[27] Hahm, H.C., Lahiff, M. and Barreto, R.M. (2006) Asian American Adolescents’ First Sexual Intercourse: Gender and Acculturation Differences. Perspectives on Sexual and Reproductive Health, 38, 28-36. http://dx.doi.org/10.1363/3802806

[28] Shin, K.R., Park, H.S. and Hong, C.M. (2010) Effects of an Educational Program about Reproductive Health Promo- 
tion on Sexual Knowledge and Attitudes of University Students from Korea. Journal of Korean Academy of Adult Nursing, 22, 448-456.

[29] Cha, E.S., Doswell, W.M., Kim, K.H., Charron-Prochownik, D. and Patrick, T.E. (2007) Evaluating the Theory of Planned Behavior to Explain Intention to Engage in Premarital Sex amongst Korean College Students: A Questionnaire Survey. International Journal of Nursing Studies, 44, 1147-1157. http://dx.doi.org/10.1016/j.ijnurstu.2006.04.015

[30] Ahrold, T.K. and Meston, C.M. (2010) Ethnic Differences in Sexual Attitudes of US College Students: Gender, Acculturation, and Religiosity Factors. Archives of Sexual Behavior, 39, 190-202. http://dx.doi.org/10.1007/s10508-008-9406-1

[31] Wetherill, R.R., Neal, D.J. and Fromme, K. (2010) Parents, Peers, and Sexual Values Influence Sexual Behavior during the Transition to College. Archives of Sexual Behavior, 39, 682-694. http://dx.doi.org/10.1007/s10508-009-9476-8

[32] Park, H.J. and Kang, S.J. (2013) Cybersex Addiction among Korean College Students: Current Status and Relationships of Sexual Knowledge and Sexual Attitude. Journal of Korean Public Health Nursing, 27, 608-618. http://dx.doi.org/10.5932/jkphn.2013.27.3.608

[33] Franklin, R.M. and Dotger, S. (2011) Sex Education Knowledge Differences between Freshman and Senior College Undergraduates. College Student Journal, 45, 199-213. 